\title{
Leer es tocar: una revisión de la materialidad del archivo en la obra de Darío Rozo Martínez
}

\section{To read is to touch: a review of the materiality of the archive in Darío Rozo Martínez' work}

DOI: https://doi.org/10.29166/tyc.v1i21.2481

\section{Sebastián Moreno Santacruz}

Estudiante del programa doctoral de Literatura y Estudios Culturales del Departamento de Español y Portugués de la Universidad de Georgetown (Estados Unidos); estudió Ciencia Política en la Universidad del Rosario (Colombia); posteriormente cursó la maestría en Literatura en la Pontificia Universidad Javeriana (Colombia), en la cual se graduó con honores.

Correo: sm3594@georgetown.edu / moreno.sebastian@javeriana.edu.co

\section{Resumen}

El objetivo de este ensayo es leer la obra y la materialidad de los archivos del ingeniero colombiano Darío Rozo Martínez (1881. 1964). Para ello, fue necesario realizar una (re)organización de la obra de este autor, diseminada por diferentes bibliotecas bogotanas, y que, en su mayoría, permanece inédita. Las correcciones que el autor dejó en sus textos, así como los tachones, las rayaduras y los desgastes en los documentos, permitieron establecer una conexión entre lo escrito y la fibra sobre la cual esta se inscribe, de modo que se introduce la dimensión material de los textos en los estudios archivísticos.

Palabras clave: archivo, marginalia, literatura de viajes, ciencia y literatura, cruce de saberes.

\section{Abstract}

This essay's objective is to read the work and the materiality of the Colombian engineer Darío Rozo Martínez archives (1881-1964). For this, it was necessary to carry out a (re) organization of this author's work, scattered in different Bogota libraries, and most of this work remains unpublished. The corrections that the author left in his texts, as well as the deletions, scratches and wear on the documents, made it possible to establish a connection between what was written and the fiber on which it is inscribed, in order to introduce the material dimension on the archives studies.

Keywords: archive, marginalia, travel literature, science and literature, crossing knowledge boundaries. 


\section{Introducción}

Todo trabajo de archivo consiste en una búsqueda y en un descubrimiento. Identificar, seguir huellas, delimitar y clasificar el rastro de los documentos hacen parte de la experiencia propia del archivo. Por ello, hacer figurar la memoria y el origen de una obra es un trabajo análogo al arqueológico. Pero, como Jaques Derrida observa en su texto Mal de archivo: una impresión freudiana (1997), esa es la primera impresión del trabajo archivístico y, usualmente, ese trabajo queda relegado a esa excavación documental en bibliotecas.

El almacenamiento, la impresión y el cifrado de las inscripciones hablan también, según Derrida, de la censura, represión y supresión de la lectura de esos textos. De esta manera, es posible preguntarse ¿cómo abordar un archivo que ha estado confinado en el sueño bibliotecario? ¿cómo proceder entonces con una obra que no solo ha permanecido enclaustrada en una colección que, irónicamente, ha estado siempre, aunque parcialmente disponible, para la consulta del público general? Tal es el caso del archivo y obra del ingeniero colombiano Darío Rozo Martínez.

Rozo Martínez nació en Bogotá el 17 de noviembre de 1881 y murió el 16 de mayo de 1964 en la misma ciudad. Se graduó como ingeniero civil de la Facultad de Matemáticas e Ingeniería de la Universidad Nacional en 1909, a la par que tomó cursos de dibujo y pintura, además de grabado en madera en la Escuela de Bellas Artes. Esa generación vivió la transición del fin de la Guerra de los Mil Días (1899-1902), un conflicto civil protagonizado por los partidos políticos Liberal y Nacional, además de la separación de Panamá de Colombia en 1903. En el periodo inmediatamente posterior a la guerra, tanto el gobierno conservador de Rafael Reyes (1904-1909) como los siguientes, heredaron un país económica y socialmente vencido. Con respecto al desarrollo económico e industrial de la época, mucho en el país estaba por hacerse con respecto a la ingeniería, a los estudios geográficos y demás ciencias que pudiesen prestar servicios o usos cívico-militares (Bazzani, 2009).

El interés que Darío Rozo Martínez mostró por diferentes áreas del conocimiento quedó registrado en diversas publicaciones académicas o científicas, y que hoy forman parte de un archivo disperso por varias bibliotecas bogotanas. La ingeniería, las matemáticas, la física, la astronomía, la geodesia y la geografía fueron campos en los cuales el intelectual colombiano dejó una producción escrita en algunas revistas de su época. No obstante, los intereses de Rozo no se circunscribieron únicamente a las ciencias naturales, dado que en sus textos brotan rasgos propios de una escritura literaria que navega entre múltiples saberes, y que arrastra consigo los registros discursivos de esas disciplinas. Durante las primeras décadas del siglo XX, en revistas bogotanas como El Gráfico o Cromos, Rozo publicó relatos y poemas, en ocasiones ilustrados por su propia mano, así como textos cortos de investigación sobre filología chibcha, tema que lo apasionó y lo llevó a emprender la escritura de un extenso poema épico que nunca llegó a publicar, en el cual aborda su interés por esa cultura.

Las copias de esos documentos quedaron al resguardo de la Biblioteca Eduardo Santos (BES) de la Academia Colombiana de Historia, la Biblioteca Nacional de Colombia (BNC) y la Biblioteca Luis Ángel Arango (BLAA), todas ubica- 
das en Bogotá. La notoriedad de Rozo ha sido perpetuada en relación con su título de ingeniero, de tal modo que las publicaciones que incluyen notas bibliográficas, además de la mención a su carrera profesional, tienen a resaltar mayoritariamente esa faceta de su vida (Bazzani, 2009; Sociedad Geográfica de Colombia 1979; Paty \& Martínez 2004). En este sentido, los comentarios sobre sus escritos literarios son tímidos y apenas citados, con la única excepción del artículo escrito por su nieto, Fernando Bazzani Rozo, titulado Vida y obra del ingeniero Darío Rozo Martínez (2009).

En este sentido, el propósito de este ensayo es presentar y explorar el archivo de Darío Rozo Martínez, resaltando las particularidades de la dimensión material de los textos. Para este propósito, he divido el ensayo en dos partes. En el primer apartado exhibiré el estado general del archivo disponible del intelectual colombiano, haciendo énfasis en el contenido de sus trabajos más representativos. El segundo apartado tendrá como propósito ahondar en las marcas propias de ese archivo, tales como las tachaduras, correcciones o anotaciones que el autor dejó en los documentos.

\section{La reorganización del archivo de Darío Rozo Martínez}

La relación entre las distintas disciplinas en la obra del ingeniero colombiano puede entenderse como un proceso de diálogo y negociación entre fuerzas que conviven en un estado de intercambios y préstamos. La tensión en la obra de Rozo Martínez no es, como podría advertirse en una primera aproximación, un estado de oposición o alteridad entre epistemes acorazadas en sí mismas, limitadas a categorías precisas e independientes. Por el contrario, la tensión a la que aludo en la obra de Martínez logra configurar un ethos que se nutre justamente de esa diferencia de saberes. Bien se podría enunciar este rasgo característico como parte de un proceso que toma un conocimiento determinado y, a partir del uso de un lenguaje específico -científico o poético-, del recurso de técnicas narrativas, del empleo de imágenes - gráficos, mapas, fotografías, dibujos- o el desarrollo de procesos estrictamente matemáticos, se reconfigura el conjunto de su obra, de manera que el resultado conduce a lugares de ambivalencia literaria.

Es posible entonces encontrar pasajes de contagio epistémicos en su obra, que se disputan entre una descripción técnica de la gradiente de una ladera, la narración del sentimiento de zozobra en un viaje en automóvil, seguido por el uso de un recurso visual fotográfico en el que interviene otra forma de dar cuenta de la narración, tal como ocurre en el texto Del Pacífico al Atlántico por la región ecuatorial de América (1956). Este texto fue publicado como suplemento del Boletín de la Sociedad Colombiana de Geografía, perteneciente a los números 13, 14 y 15 en 1956.

El texto narra el viaje que el autor realizó entre 1928 y 1929, como parte de su trabajo con la Comisión de Límites Colombiana ${ }^{1}$, con el propósito de trazar las fronteras con la República del Perú y Bra-

1 En esa época, la dirección del trabajo estaba a cargo de la Oficina de Longitudes y Fronteras. Posteriormente se creó el Instituto Geográfico Militar y Catastral, que luego se renombró como Instituto Geográfico Agustín Codazzi. 
sil. Rozo no indica exactamente cuándo comenzó su viaje -únicamente revela el año de inicio- pero sí cuándo terminó: el 5 de junio del año mencionado. Durante ese lapso, Rozo narra las impresiones que tuvo del viaje, transitando entre el lenguaje descriptivo y el narrativo, e incluso en algunos apartados, llega a usar un lenguaje técnico con respecto a la información que entrega al lector. Rozo también hace uso de un catálogo de fotografías que expanden la lectura del texto, pero resulta difícil saber cuáles fueron tomadas por él, quizá por algún miembro de la Comisión o si fueron extraídas de algún archivo.

Si bien es posible inferir el comienzo del viaje de Rozo desde Bogotá, el autor fija como punto de partida de la expedición el puerto del Callao. Después de un viaje en tren desde Lima hasta Tarma, marcado por la monotonía del paisaje, es justo en esta parte del texto en la cual se encuentra una de las citas más reveladoras en relación con los espacios de tensión ya mencionados. El cambio de la forma de narrar se da abruptamente cuando el medio de transporte cambia de tren a automóvil. De esta manera vemos que el tono de Rozo integra una descripción más técnica en su observación:

Desde el Callao hasta Oroya el "Ferrocarril Central” recorre 222 kilómetros; en el primer trayecto de 76 kilómetros, hasta San Bartolomé, tiene una pendiente media del 2\%, y de ahí hasta Oroya la gradiente $^{2}$ es del $4 \%$. En esta parte de la vía hay 66 túneles, el más importante es el de Galera, con kilómetro y medio de largo y que orada el monte Meiggs, cerro que lleva el nombre en memoria del ingeniero americano Enrique Meiggs, quien concibió la obra y le dio principio en 1870 llevándola hasta Chicla. Se cuentan en este trayecto entre el Callao y oroya 67 puentes de hierro de diversos sistemas, el mayor mide 175 metros de largo. El ancho de la vía es de 1.435 milímetros y las locomotoras que admite no deben pesar más de 125 toneladas y arrastran un tonelaje aproximadamente igual. (1956, p. 14)

Justo después de esta concretísima descripción, Rozo desanda la voz cuantitativa para describir el recorrido en automóvil, desde Oroya a Tarma:

Venía ya la noche cuando nuestro automóvil de alquiler viajaba solitario por aquellas regiones desamparadas; las curvas del camino se perdían entre las sombras y el cielo que cubría el paisaje, era de un gris casi negro [...].

Pronto invadió la angustiosa noche, y el último vislumbre de la tarde no dejó columbrar ni una choza, ni un sendero, solo se veía el camino que serpeaba por el flanco de las enormes cañadas, hasta perderse en las sombras de la lejanía y del resto de colinas escuetas, cerros rocosos unos después de otros hasta esfumarse en la tiniebla de las nubes.

En breve todo fue oscuro; sólo se escuchaba el fragor de la máquina: íbamos descendiendo y las sombras circundantes hacían pensar en abismos sin término [...] se oye el lejano ladrido de un perro y luego un murmullo de aguas que corren entre pedregales, ruidos familiares que son como un sedante para el ánimo [...]. (Ibid., p. 14)

Los límites entre una narración y otra ponen en tensión la ficción y la realidad. Estos espacios de tránsito son lugares de indecisión entre la descripción y la narración. Esto lleva a que se vuelva indistinguible la separación entre el lugar de lo real y de lo ficticio. Allí, en el texto, aparece una fotografía panorámica de Tarma (imagen 1), la cual sitúa al lector en el lugar aproximado de la acción.

2 Gradiente: razón entre la variación del valor de una magnitud en 2 puntos próximos y la distancia que las separa. 


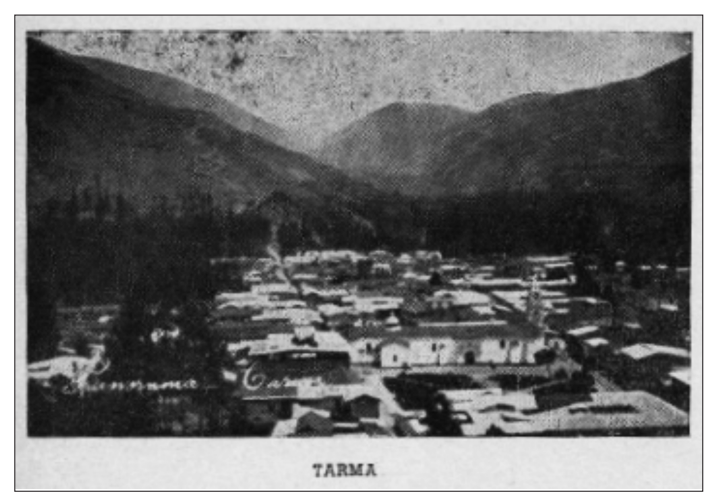

Imagen 1: Imagen de Tarma (Rozo, 1956, p. 16).

Estos lugares de (des)encuentro, muchas veces ambiguos en la obra de Rozo Martínez, no responden en todas las ocasiones a una apuesta o intención deliberada por parte del autor de encauzar o enraizar diversas formas de enunciación del conocimiento. Las tensiones que se generan en diversos espacios del conjunto de la obra de Rozo Martínez no son, en últimas, un mero producto del cruce de voces que él es capaz de apropiar, sino que desbordan la capacidad de previsión que el autor pudo llegar a contemplar sobre su obra.

Esta convivencia de voces no se presenta únicamente en el texto anteriormente citado, sino que aparece también en Mitología y escritura de los chibchas: Segunda edición aumentada (1938) o el artículo Revaluación de la ciencia y del conocimiento del Universo (1922a), por mencionar algunos. Los contagios de saberes se observan también en otros aspectos de la obra del intelectual colombiano. Aquellos contagios y fracturas que caracterizan su obra no brotan únicamente en los textos propios de una literatura ampliada que, leída así, resignifica los lugares de enunciación de los documentos, sino que también se manifiestan en el discurso marginalizado que brota de ellos dadas sus características heterogéneas.

La labor de examinar y leer el archivo de Rozo Martínez implica una (re)organización de este, por la peculiaridad de los documentos. Durante el proceso de investigación y recopilación de las fuentes, encontré marcas singulares que interpelaban tanto a los documentos como a la lectura misma de esos materiales. Estas particularidades propias en la materialidad del archivo radican principalmente en una serie de inscripciones que abarcan notas a mano, tachaduras, adhesiones con cinta en las márgenes de los textos, así como ilustraciones -mapas y dibujos-, es decir, existe una marginalia propia de los documentos que se presenta al lector como lugar de encuentro desde $y$ hacia el borde de las hojas. En este sentido, se hizo evidente que el archivo en sí mismo también pedía ser leído. Fue posible entonces plantearme que las manifestaciones palpables y singulares de la materia en los documentos exigían una operación de lectura propia para acercarme a la obra del autor, esta vez desde una dimensión dérmica de la lectura ${ }^{3}$.

En los documentos dispersos en las diferentes bibliotecas consultadas, aparecieron algunos textos de Rozo que daban cuenta de un trabajo de archivo realizado por el propio autor con respecto a algunos documentos de la época de la Colonia, así como un registro fotográfico que ayudaba a consolidar otros escritos. Uno de los documentos que menciona su trabajo con el archivo es Leyendas santafereñas - Reliquia ensangrentada (1921c), que inicia de la siguiente manera:

3 Uso la imagen que propone Javier Guerrero en su texto Piel de archivo (2015), cuya critica del archivo parte de considerar su dimensión material o dérmica de los documentos como parte de la propia materia escritural, de modo que su lectura involucra el tacto y el uso de las manos. 
El manuscrito que por casualidad encontré, está en el tomo XXII de Misceláneas, perteneciente al Archivo Colonial, y en él se relata un hecho que comienza con estas palabras: "A un padre de nuestra religión aconteció, etc.,» y en todo lo escrito no llega a nombrársele; yo casi podría demostrar que he hallado el nombre, y aquí se lo daré para poner algo de vividez a mi narración, aunque sin alterar en nada lo primordial del acontecimiento contado por el viejo papel casi ilegible. (p. 179)

El relato, tal y como lo presenta el autor, es una reescritura de una crónica colonial -acontecida probablemente en la primera mitad del siglo XVII-, intervenida por él para dar cadencia a la narración. El texto relata la historia de don Miguel de Echandía, mozo de buena prosapia, quien tras buscar las atenciones de dos mujeres santafereñas de distinguidas familias, - una de ellas hija del Gobernador- termina rechazado por ambas y, tras la decepción amorosa, decide entregarse al hábito con los hermanos franciscanos. Las historias de Rozo sobre leyendas o anécdotas olvidadas de la colonial Santafé surgen de su trabajo de archivo.

Otro de los textos que contemplan un trabajo de archivo hace parte de la misma serie Leyendas santafereñas - Los perros fantasmas (1922), cuya naturaleza es similar a la anterior, con la diferencia de que este fue escrito completamente por Rozo. El origen del escrito surge, como se lee en la publicación, del relato de una leyenda contada por el jardinero de una casa de campo, la cual contiene una "antigua maldición" sobre los perros que habitasen en esa casa. Como el mismo autor escribe, su fascinación por este tipo de historias lo llevó a escuchar y a profundizar en la historia, de tal suerte que la narración inicia como parte de la memoria oral del jardinero, descrita como:
[...] descarnada y sin fechas; empero, por el nombre del galán y por haber mencionado a un Arzobispo muy aficionado a las cacerías, he logrado -después de algunos años de labor paciente, digna de un académico de la Historia-, reconstruir la antigua escena que dio origen a la leyenda y por haberme parecido pintoresca voy a relatar. (1922, p. 722)

El punto de partida para la exploración de la dimensión material del archivo vino luego del hallazgo del poema épico Gesta en Hispanoamérica (1954), que contiene en el cuerpo del documento buena parte de las anotaciones a mano y otras trazas manuscritas del autor, y que además se encuentra en excelente estado de conservación. Al revisar el texto, encontré tres notas mecanografiadas por Rozo, dos de las cuales invitaban al lector a corregir un error sobre la palabra "Sugunsua", de voz chibcha, cuya redacción correcta sería "Suguasua" (imagen 2); la tercera nota es una declaración de cesión de los derechos del poema, así como de la segunda edición aumentada de Mitología y escritura de los chibchas para su eventual publicación. Las tres notas tienen estampada el facsímil de la firma del autor.(Imagen 2)

A medida que fui explorando el libro, encontré tachones sobre algunos versos, incluso corregidos en su totalidad a lápiz entre renglones, evidenciando una reescritura en algunos pasajes de la obra. No resultó difícil reconocer que esos cambios fueron hechos por el propio autor, al comparar su trazo con otras notas a mano. En este sentido, Gesta en Hispanoamérica (1954) y Mitología y escritura de los chibchas: Segunda edición aumentada (1938), presentan características singulares, teniendo en cuenta que el primer documento es la única copia disponible para el público general, y que el segundo contiene los anexos de la edición ampliada (Imagen 3). 


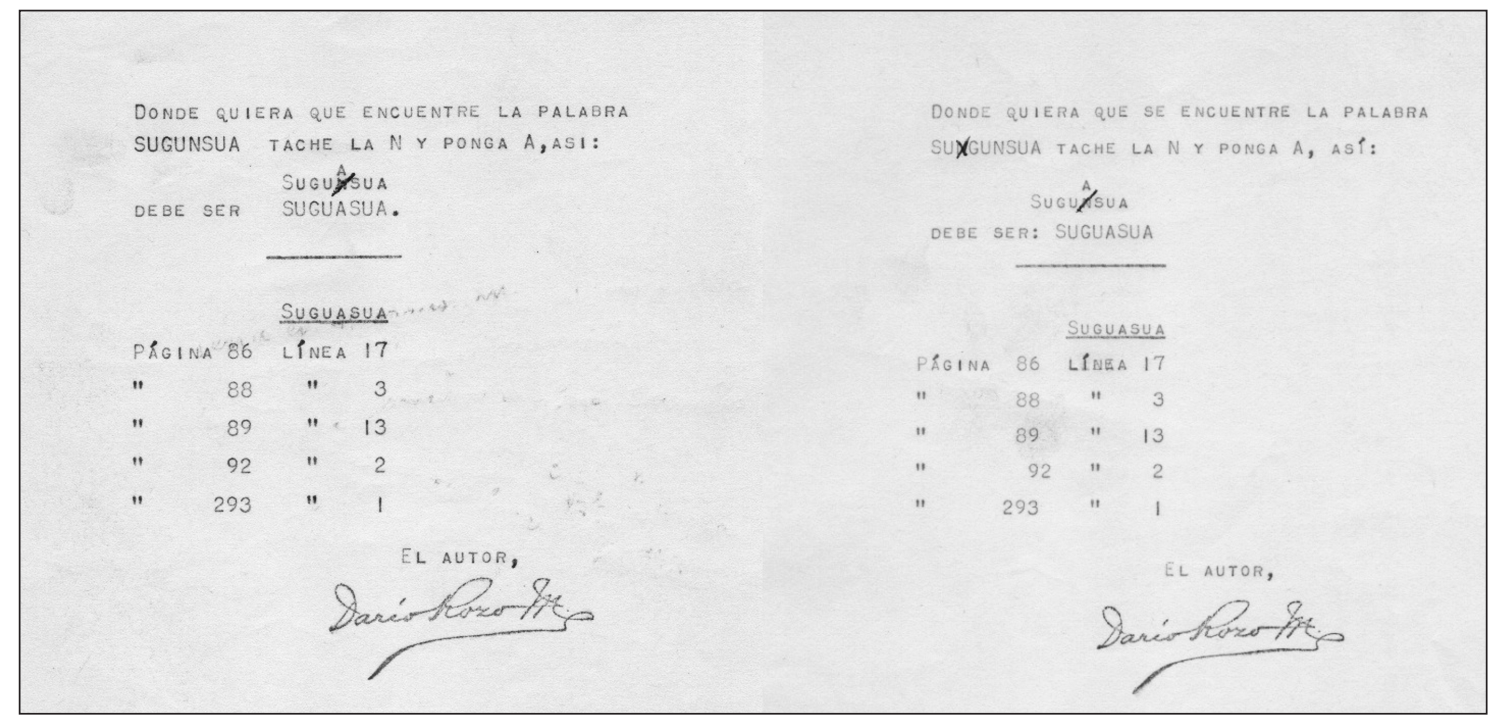

Imagen 2: notas que invitan al lector -y posible editor- a corregir el error (encontradas en Rozo, 1954).

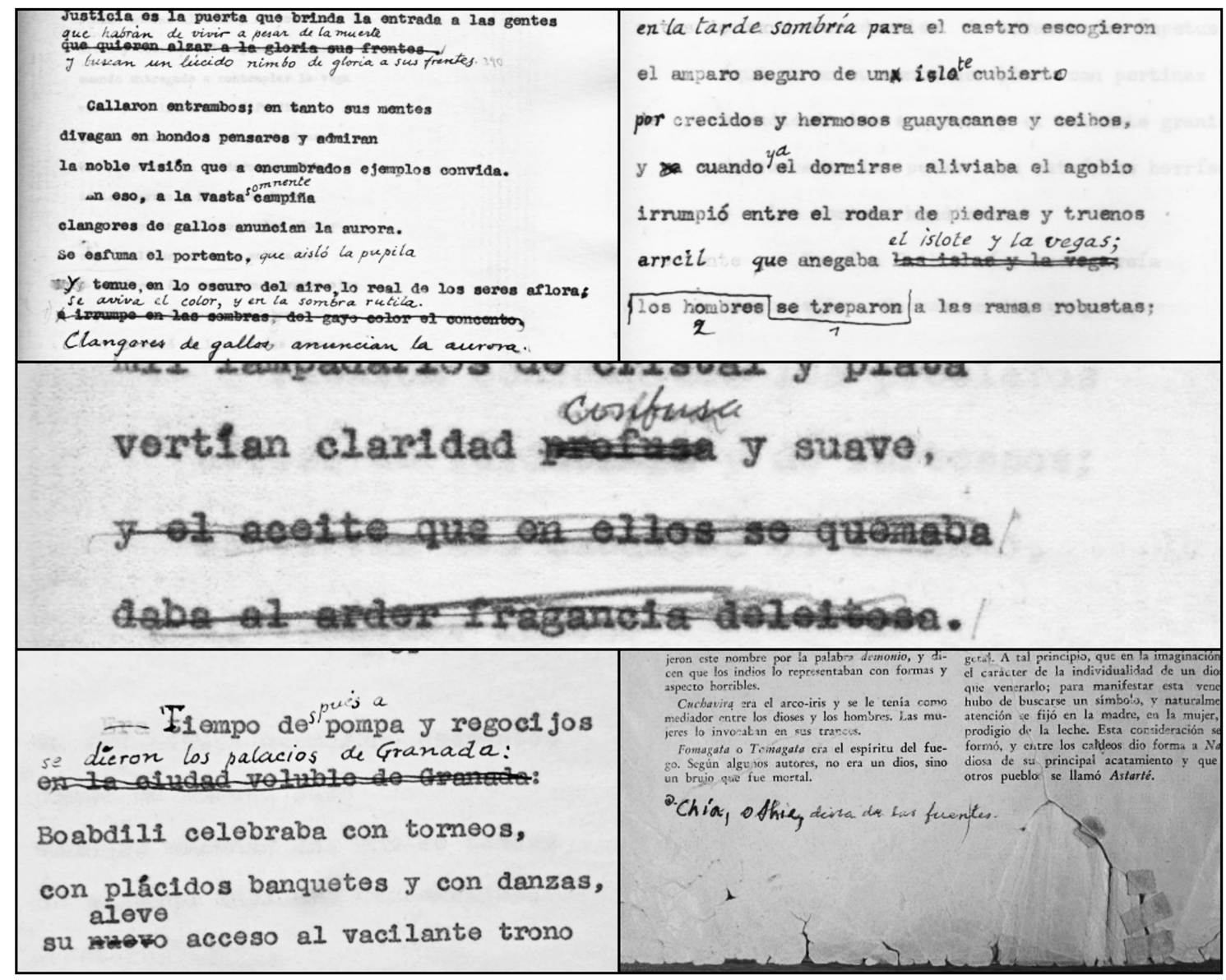

Imagen 3: Correcciones y tachaduras hechas por el autor en Gesta en Hispanoamérica (1954) y Mitología y escritura de los chibchas (1938) -segmento inferior derecho-. En esta última, la anotación añadida junto con la sutura plástica en la hoja. 
Los textos científicos de Rozo, Nuevo concepto de la relatividad einsteiniana (1956b), La electricidad atmosférica y los rayos cósmicos (1956a), Consideraciones sobre las mejores condiciones de observación en astronomía geográfica (1958), El campo gravitacional explicado por la ecuación de onda (1960) e Historia del átomo nuclear y los átomos artificiales (1960a), se encuentran reunidos y catalogados por la BLAA como "Miscelánea 902".

En relación con otras publicaciones de Rozo, en la BNC aparecen en microfilme sus publicaciones en la revista $E l$ Gráfico $^{4}$, la cual circuló entre los años 1910 y 1941. Estas publicaciones cuentan con ilustraciones hechas por el propio escritor para algunos de sus textos, entre ellos Leyendas santafereñas - La reliquia ensangrentada (1921a), Leyendas santafereñas - Los perros fantasmas (1922) y Revaluación de la ciencia y del conocimiento del universo (1922a).

Dadas estas características, la manera en la que propongo leer estos textos involucra la forma y sensibilidad propia de la materia de esos documentos. La experiencia de poner las manos sobre el archivo permite abrir una serie de preguntas en torno a cómo se debe trabajarlo, qué nos dicen esas particularidades sobre la historia íntima del texto, de su factura y hechura material, y qué implicaciones existen cuando este ha sido escasamente revisado. Los microfilmes de la revista $E l$ Gráfico poseen una materialidad propia pero cuya lectura no implica una experien- cia táctil sino visual de las ilustraciones y textos. En este sentido, los documentos disponibles -y dispersos- de Rozo posibilitan un paralaje del sentido entre el discurso científico y literario, hacia la exploración de lo sensible como expresión de un sensorio visual y táctil del archivo.

\section{Unión, exceso y herida}

Si el archivo es la piel de un cuerpo -o también un órgano sin cuerpo (Guerrero, 2015) -, los anexos que se hacen a ese archivo son injertos y a la vez brotes que se realizan en esa piel: el cuerpolibro, el cuerpo-archivo se expande, se desborda, existe por fuera de sus márgenes y de sus propios límites. Estos lugares de incertidumbre de los documentos son la materia con la cual es posible realizar "[...] un cambio de piel, que aunque a su vez se hace metáfora del cuerpo, tal condición metafórica solo reside en su dimensión material" (Guerrero, 2015, p. 47). Todos los cambios que se realizan en el documento original dan paso a un proceso que corrompe esa materialidad primaria, de modo que la manipulación -adecuada o no- de los documentos deviene en singularidad como forma de las marcas del desgaste, heridas como trozos ausentes de las hojas, y los esfuerzos por fijar el desgarre -el uso de la cinta, de la costura- genera con el tiempo otro tipo de inscripción en la hoja, suturas sobre las fracturas que pueden ser leídas como líneas de fuga del propio documento.

\footnotetext{
4 La revista El Gráfico fue una revista semanal ilustrada que se publicó los sábados en Bogotá. Paula Andrea Marín Colorado (2016) explica que "[...] El Gráfico se dirigía más a una clase media en formación, con limitadas capacidades de consumo, a unos lectores que no poseen una cultura letrada significativa y que se siente más cómoda leyendo autores nacionales que extranjeros” (p. 188).
} 
Esta fragilidad no solo es parte natural de la materia que se desgasta, así se injerten otros componentes que busquen extender la vida del registro, sino que remiten a la noción de lo que es archivado y documentado con el fin de perdurar, lucha contra la pérdida de la memoria y la muerte de aquello que ha sido consignado. En este sentido, Derrida en Mal de archivo: una impresión freudiana (1997) aclara que:

No hay archivo sin lugar de consignación, sin una técnica de repetición y sin una cierta exterioridad. Ningún archivo sin un afuera.

[...] si no hay archivo sin consignación en algún lugar exterior que asegure la posibilidad de la memorización, de la repetición, de la reproducción o de la re-impresión, entonces, acordémonos también de que la repetición misma, la lógica de la repetición, e incluso la compulsión de la repetición, sigue siendo, según Freud, indisociable a la pulsión de la muerte. Por tanto, de la destrucción. Consecuencia: en aquello mismo que permite y condiciona la archivación, nunca encontraremos nada más que lo que expone la destrucción, y en verdad amenaza con la destrucción, introduciendo a priori el olvido y lo archivolítico en el corazón del monumento. En el corazón mismo del «de memoria». El archivo trabaja siempre y a priori contra sí mismo. (pp. 19-20) [las cursivas son del autor]

Tenemos así que la materia se vale de sí para perdurar y ser reproducida, y la técnica con la que se archiva aquello que ha sido valorado para ser conservado, no escapa en todo caso a la amenaza de la desaparición y la muerte.

Aquellas zonas señalan la marcha entre la conservación y la muerte de la materia de lo archivado (imagen 4). Los anexos y suturas no hacen parte del índice del cuerpo y vuelven materia flexible a la propia materia, de modo que, al abrir, al ver el papel a contraluz, al palpar, al leer entre y bajo líneas y tachaduras, el objeto de la lectura se transforma, se mueve constantemente entre sentidos y sensaciones. Las partes en las cuales los ojos fijan la atención requieren inmediatamente un segundo examen que solo es posible realizar por medio de la piel lectora (las manos), de modo que la piel leída (el archivo) se abre sobre la historia de su propio registro. Por esta vía, el papel se satura de contenidos y de imágenes, y esta reorganización de lo sensible exige la experiencia palpable de las dos pieles. (Imagen 4).

Por un lado, recorrer esa geografía de las inscripciones o las marcas del archivo abre la puerta a pensar el texto más allá del contenido escrito y se descifra, por el otro, la suerte de lo que la hoja consiga, lo que el autor y el tiempo -de forma consciente o no- otorgaron al documento.

Las inscripciones, notas, tachones y enmendaduras, así como los anexos postescriturales, entran a formar parte del cuerpo de los documentos, con la característica esencial de no ser, a la vez, parte del mismo. Esa materia anexa, posterior, imprevisible, marginalizada del espacio

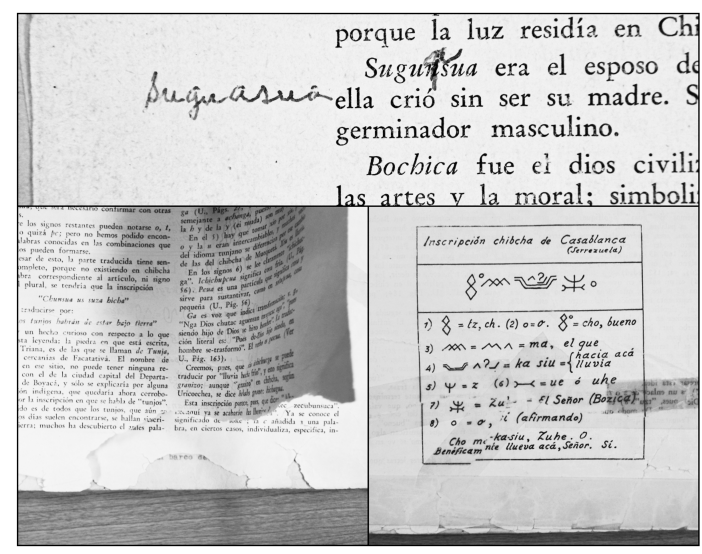

Imagen 4: Detalles de la materialidad del archivo en Mitología y escritura de los chibchas (1938) 
central de la hoja, desborda a la propia materia a la cual está sujeta. Quiero leer este devenir del archivo en el sentido en que Deleuze lo plantea cuando habla de las líneas de fuga y del devenir, puesto que estos surcos en la materia:

[...] no son fenómenos de imitación ni de asimilación, son fenómenos de doble captura, de evolución no paralela, de bodas entre dos reinos. Y las bodas son siempre contra natura. Las bodas es lo contrario a una pareja. Se acabaron las máquinas binarias: pregunta-respuesta, masculino-femenino, hombre-animal, etc. (Deleuze \& Parnet, 1980, p. 6)

La lectura que se hace sobre el documento se desdobla así de "las máquinas binarias" que propone Deleuze: ya no se trata únicamente de ver y leer en el marco de la relación tachado-corrección, roturaenmienda, texto-ausente como imposibilidad de lectura. Al respecto, se puede entender el documento como un cuerpo que es extensión del autor, pero también del archivo mismo, implica comprender que la materia escritural se hace presente cuando otra piel lo toca o lo habita. Podría decirse que quien accede al cuerpo del documento y lo palpa requiere hacer uso de las manos, de la vista e incluso del olfato para leer ese cuerpo archivado. Es allí donde ese registro preservado en el domicilio bibliotecario se hace materia legible, no en el significado de las palabras, puesto que ese no es su único sentido de lectura, sino también en el devenir del encuentro entre la piel lectora y la piel leída, saliendo así del adormecimiento, del sometimiento que implican las técnicas y políticas de conservación que recaen sobre el archivo.

Y como es usual, sobre los cuerpos recaen tabúes, interrogantes, inconsisten- cias del sentido del cuerpo-otro, que se manifiestan en normas o procedimientos que buscan evitar el contagio, aunque este en realidad nunca sea del todo evitado: el requerimiento del uso de guantes y tapabocas, la imposibilidad de utilizar flashes o luces de escáner buscan preservar una materialidad determinada, pero no hay acercamiento y contagio que no involucre un desgaste, preservación sin usura de lo que es palpable, entendimiento sin el roce creativo de los sentidos: es necesario desnudar ambos cuerpos para que se abra la posibilidad de que los cruces de la materia generen o devengan en el asunto de lo leído, como una cópula sensorial de la experiencia.

Las copias de los textos Mitología y escritura de los chibchas y Gesta en Hispanoamérica que residen en la BLAA dan cuenta del devenir de esos archivos; la condición del documento no se corta, ni se deshace o se rompe: hay en la ausencia de la condición original de la hoja, en la deliberada o no reformulación de su contenido, un acoplamiento del sentido propio del archivo. Cuando la lectura se interrumpe, no se consume ni deja de ser "posible", sino que cambia de ritmo, crece o decrece su velocidad, cambia de magnitud por completo. Hay que pensar y leer de otras formas para seguir dando rienda a la lectura previa. ¿Qué hay para ver, cómo se debe tocar -delicadamente, superficialmente- para seguir en la lectura? La prioridad del encuentro con el documento ya no es netamente extractiva, hermenéutica, sino que se abre a la necesidad de (re)poner, (re)componer y dirigir las "malformaciones" o "mutilaciones" del archivo como parte del archivo mismo, del cuerpo natural del texto.

Las restauraciones y los anexos, como en el caso de Mitología y escritura 
de los chibchas, que implican la posibilidad de una segunda edición aumentada, o las marcas hechas por la mano del autor, son entradas y salidas de un "original" ya ausente, pues el documento inicial ha sido sobrepuesto a su propia materia y resulta imposible separar lo "modificado" de lo "original": esos excesos y heridas son el entre de ambos estadios. El documento se lee en clave de su propio devenir. Incluso, si la materia de la unión fuese retirada, presuntamente borrada, restaurada, quedarían allí las huellas de su pasado. La marca del uso del archivo es una marca en el cuerpo archivado imposible deshacer. Hablar de la conservación de cualquier documento es también elaborar un relato sobre su devenir.

En la primera página del Gesta en Hispanoamérica encontramos una dedicatoria que funciona como nota introductoria, escrita a mano, y es también la más larga hecha por Rozo en todos los documentos consultados (imagen 5). En esta dedicatoria es posible ver cómo Rozo escribía para un lector-receptor ausente, imaginado, presentándose él mismo como el autor. Es posible afirmar que hicieron falta 56 años para que la nota finalmente tuviese un destinatario externo, real. (Imagen 5).

El encuentro de la piel leída y la piel lectora marcó el momento en el cual el archivo dejó de ser meramente la fuente primaria, para poner en consideración, a la vez, la dimensión dérmica como forma de lectura mediante el órgano táctil. El archivo me exhortó a pasar el ojo y la mano

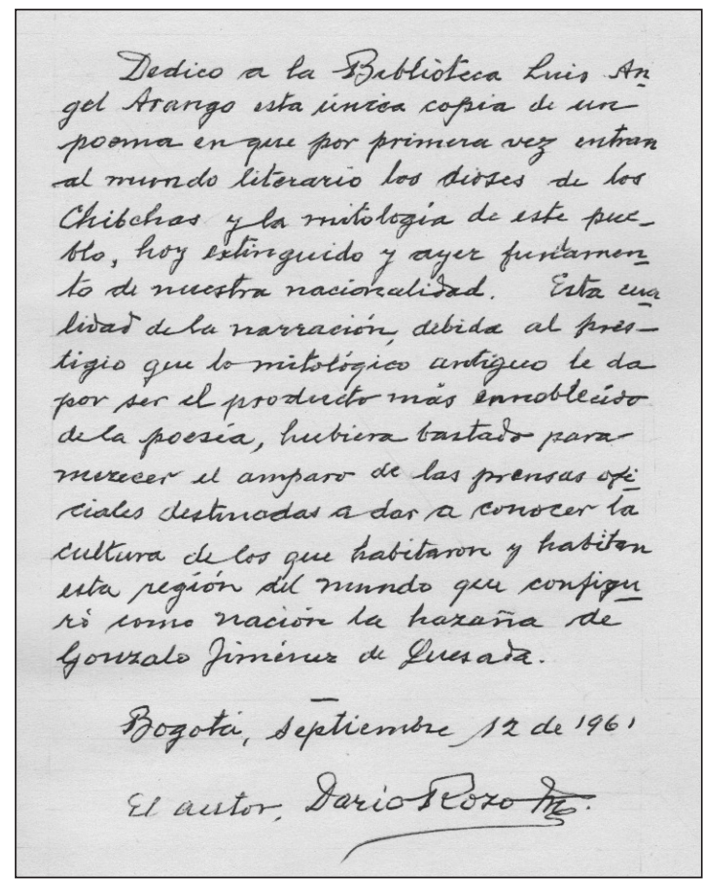

Imagen 5: Dedicatoria y firma del autor en Gesta en Hispanoamérica (1954).

sobre sus comisuras, suturas, las tachaduras o reescrituras, para recalcar que existe una relación de sentido literario entre lo escrito y la fibra sobre la cual se inscribe. El resultado del encuentro inesperado de las cualidades de este archivo - por tanto, de su escritor- moldearon esa lectura de traspaso, de préstamo y contagio en las formas de lectura.

Rozo, en una conferencia publicada en la revista Anales de Ingeniería, llamada La Amazonía colombiana y las comisiones de límites (1935), ofrece una imagen de cómo la materia puede adquirir nuevos usos, lo que en mi trabajo derivó en formas de lectura alternativas. En

5 "Dedico a la biblioteca Luis Ángel Arango esta única copia de un poema en que por primera vez entran al mundo literario los dioses de los Chibchas y la mitología de este pueblo, hoy extinguido y ayer fundamento de nuestra nacionalidad. Esta cualidad de la narración debida al prestigio que lo mitológico antiguo le da por ser el producto más emblemático de la poesía, hubiera bastado para merecer el amparo de las prensas oficiales destinadas a dar a conocer la cultura de los que habitaron y habitan esta región que configuró como nación la hazaña de Gonzalo Jiménez de Quesada. Bogotá, septiembre 12 de 1961. El autor, Darío Rozo Martínez.” 
uno de los viajes de la Comisión encargada de delimitar la frontera con el Brasil, los miembros de las comisiones se toparon en la ribera del río Yavarí -cerca a Tabatinga- con una fortificación militar hecha por los portugueses y luego traspasada a la corona española en la época de la Colonia, de modo que "De las ruinas del antiguo cuartel, tomamos el ladrillo que sirvió para construir los hitos de esta región y del Apaporis" (Rozo, 1935, p. 347). Los hitos, que son unas pequeñas estructuras que sirven para marcar los puntos geográficos de las fronteras, fueron hechos a partir de ladrillos que cumplieron originalmente otro propósito, fueron extraídos de sus coordenadas iniciales para luego funcionar dentro de un nuevo sistema de comunicación. Gracias al estudio de la escritura chibcha, Rozo entendió que el ejercicio de interpretación es tanto un desafío como búsqueda de aquello que ha sido omitido y relegado al olvido, por ello él escribe que:

En estos achaques de leer inscripciones antiguas son más los que se equivocan que los que aciertan, pues muy grande es la parte que la imaginación toma al estudiar los signos olvidados ya y las más de las veces desconocidos; pero esto, a más de curioso, puede abrir un resquicio por donde penetre la luz [...]. (Rozo, 1921, p. 254) [las cursivas son mías]

La transfiguración de la materia renueva sus usos, y en cuanto a la lectura del archivo, esos nuevos usos hacen parte de la iterabilidad $^{6}$ de un texto, que más que repetirse a sí mismo, se reitera como otro, se reitera en la alteridad. El relato del archivo no termina de narrarse por sí mismo, no se agota en sí y está abierto al desvío, al reajuste de lo sensible, a traer al frente y leer, en conjunto con lo escrito, aquello que ha sido susceptible de ser ignorado.

6 Derrida en Firma, acontecimiento, contexto (1971), expone que la raíz etimológica de iterabilidad -iter- proviene del sánscrito itara, que designa «otro», de modo que él liga la noción de la repetición con la alteridad. En este sentido, la posibilidad de la repetición está implícita en cualquier tipo de código o de clave comunicable: "Toda escritura debe, pues, para ser lo que es, poder funcionar en la ausencia radical de todo destinatario empíricamente determinado en general” (Derrida, 1971, p. 357). 


\section{Textos y contextos $\mathrm{N}^{\mathrm{O}} 21$}

\section{Bibliografía}

Bazzani, Fernando. (2009). Vida y obra del ingeniero Darío Rozo Martínez (1891-1964). En Academia Colombiana de Historia de la Ingeniería y de las Obras Públicas. (2009), Apuntes para la historia de la ingeniería en Colombia (123-155), Bogotá: Editorial Códice.

Deleuze, Gilles \& Parnet, Claire. (1980). Diálogos. Valencia: Pre-Textos.

Derrida, Jacques. (1989). Firma, acontecimiento, contexto. En Derrida, Jacques. Márgenes de la filosofía (347-372), Madrid: Cátedra.

. (1997). Mal de archivo: una impresión freudiana. Valladolid: Editorial Trotta.

Guerreo, Javier. (2015). Piel de Archivo. Revista Dossier, (29) 46-59. Recuperado de: http://www.revistadossier.cl/pielde-archivo/

Marín, Paula. (2016). Diversificación del público lector en Bogotá (1910-1924). Un análisis de las revistas ilustradas El Gráfico y Cromos. Historia y Memoria, (13), 185-214. Recuperado de: https://revistas.uptc.edu.co/index.php/historia_memoria/article/view/5204

Paty, Michel \& Martínez-Chavanz, Regino. (2004). Formación y desarrollo de la cultura científica en Colombia: la física de 1880 a 1940. En Arboleda, Luis Carlos. \& Paty, Michel. (Ed.), Formación de la Cultura científica en Colombia: ensayos sobre Matemáticas y física (pp. 115-152) Recuperado de: https://halshs.archives-ouvertes.fr/halshs00185958/document

Rozo, Darío. \& Bernal, Cristóbal (1918). Alfarjes santafereños. Bogotá: Casa Editorial de Arboleda y Valencia.

Rozo, Darío. (1921). Iniciación en la paleografía chibcha. Cromos, 11 (255), 254-256.

(1921a). Leyendas Santafereñas - La Reliquia Ensangrentada. El Gráfico, 11 (562), 179-180.

(1922). Leyendas Santafereñas - Los perros fantasmas. El Gráfico, 12 (596), 722-724.

(1922a). Revaluación de la ciencia y del conocimiento del Universo. El Gráfico, 11 (586), 574-575.

(1935). La Amazonía colombiana y las comisiones de límites. Anales de Ingeniería, 43 (498) 345-351.

(1938). Mitología y escritura de los chibchas. Segunda edición aumentada. Bogotá: Imprenta Municipal.

(1943). Diálogo de la Hedimaquia. Revista de la Academia Colombiana de las Ciencias Exactas, Físicas y Naturales, 4 (15), 305-319. Recuperado de http://www.accefyn.com/revista/Vol_4/No15/Dialogo_dela_hedimaquia.pdf

(1954). Gesta en Hispanoamérica. Bogotá.

(1956). Del Pacífico al Atlántico, por la región ecuatorial de Colombia. Bogotá: Sociedad Geográfica de Colombia.

(1956a). La electricidad atmosférica y los rayos cósmicos. Revista de la Academia Colombiana de las Ciencias Exactas, Físicas y Naturales, 9 (36-37), 280-287.

(1956b). Nuevo concepto de la relatividad einsteiniana. Revista de la Academia Colombiana de las Ciencias Exactas, Físicas y Naturales, 9 (36-37), 253-261.

(1958). Consideraciones sobre las mejores condiciones de observación en astronomía geográfica. Revista de la Academia Colombiana de las Ciencias Exactas, Físicas y Naturales, 10 (40), 171-174.

(1960). El campo gravitacional explicado por la ecuación de onda. Revista de la Academia Colombiana de las Ciencias Exactas, Físicas y Naturales, 11 (43), 125-129. 
(1960a). Historia del átomo nuclear y de los átomos artificiales. Revista de la Academia Colombiana de las Ciencias Exactas, Físicas y Naturales, 11 (42), 3-15.

Sociedad Geográfica de Colombia (1979). Nota necrológica. Boletín de la Sociedad Geográfica de Colombia, 34 (114), 1 -

9. Recuperado de: https://sogeocol.edu.co/documentos/dario_rozo.pdf 